\title{
Tobin Meets Oates: Solidarity and the Optimal Fiscal Federal Structure
}

\author{
Xavier Calsamiglia \\ Department of Economics and Business \\ Universitat Pompeu Fabra and Barcelona GSE \\ Ramon Trias Fargas 25-27, 08005 Barcelona, Spain \\ xavier.calsamiglia@upf.edu \\ Teresa Garcia-Milà \\ Department of Economics and Business \\ Universitat Pompeu Fabra and Barcelona GSE \\ Ramon Trias Fargas 25-27, 08005 Barcelona, Spain \\ teresa.garcia-mila@upf.edu \\ Therese J. McGuire \\ Management and Strategy Department \\ Kellogg School of Management \\ Northwestern University \\ 2001 Sheridan Road, Evanston, IL, 60208, USA \\ and \\ Institute for Policy Research \\ Northwestern University \\ therese-mcguire@,northwestern.edu
}

Revised July 2010

We wish to thank conference participants at the University of Kentucky IFIR and CESIfo Conference on New Directions in Fiscal Federalism; seminar participants at the Federal Reserve Bank of Chicago; participants at the Workshop on Taxation, Public Provision and the Future of the Nordic Welfare Model under the auspices of the Labour Institute for Economic Research, Helsinki, Finland; and Andreu Mas-Colell, Efraim Sadka, and Jaume Ventura for very useful comments. Garcia-Milà and Calsamiglia acknowledge support from the Spanish Ministerio de Educación y Ciencia (SEJ2007-64340 and SEJ2006-09993). 


\title{
Tobin Meets Oates: Solidarity and the Optimal Fiscal Federal Structure
}

\begin{abstract}
We explore the implications for the optimal degree of fiscal decentralization when people's preferences for goods and services, which classic treatments of fiscal federalism (Oates, 1972) place in the purview of local governments, exhibit specific egalitarianism (Tobin, 1970), or solidarity. We find that a system in which the central government provides a common minimum level of the publicly provided good, and local governments are allowed to use their own resources to provide an even higher local level, performs better from an efficiency perspective relative to all other systems analyzed for a relevant range of preferences over solidarity.
\end{abstract}

JEL codes: H42, H77

Keywords: fiscal decentralization, specific egalitarianism, solidarity, externalities. 


\section{Introduction}

Tobin (1970) challenges the seemingly accepted notion among economists that it is more efficient to redistribute income than to provide benefits in kind to people with meagre means. His argument applies to goods and services that are important in determining a person's opportunity to succeed economically, to contribute to society, and to compete in life. These goods and services, he argues, should be provided more equally than people's abilities to pay for them. The right to vote in free elections is an important example. Other examples may include basic nutrition, a satisfactory level of education, adequate housing, and tolerable health care. Tobin reasons that society may want a more equal distribution of these goods and services than an unfettered private market might deliver in order that people of different means and from disparate backgrounds might have more equal chances of success. He defines the concept of "specific egalitarianism" as "the view that certain specific scarce commodities should be distributed less unequally than the ability to pay for them" (Tobin, 1970, page 264). The "certain specific" characterization is an important aspect of Tobin's idea: people have egalitarian preferences not over all goods, but only over a select few, those that strongly influence people's chances to succeed in life. ${ }^{1}$

We find plausible the idea that education and health care are services that fit within Tobin's framework; access to adequate education and satisfactory health care seem necessary for people to have the opportunity to succeed. These two services are two of the most important services provided by government today; in the developed world they represent a significant share of government expenditures and, in the case of health care, one of the fastest growing expenditure categories. ${ }^{2}$ Responsibility for delivery of these publicly provided services rests with the central government in a number of countries and with subnational governments in others. In order to address the concern for a less unequal distribution of these publicly provided services we ask one of the classic questions of fiscal federalism (Oates, 1972): should public provision of services

\footnotetext{
${ }^{1}$ Preferences for specific egalitarianism are quite different from preferences for a more equal distribution of income. The former seeks a more egalitarian distribution of the goods and services that determine the opportunity to earn income and prosper, while preferences for a more equal distribution of income focus on outcomes and may result in policies that introduce perverse incentives for work, saving and investment.

${ }^{2}$ See Gruber (2005) and OECD (2008a, 2008b).
} 
such as education and health care be decentralized or centralized? More precisely, what is the optimal fiscal federal structure for publicly provided services that fall within Tobin's domain of “equality of distribution" (Tobin, 1970, p. 266)?

We formalize Tobin's idea of specific egalitarianism and explore its implications for the design of the fiscal federal system. In the spirit of Oates (1972), we examine systems with multiple levels of government operating under different intergovernmental fiscal arrangements. We construct a model with local and central governments where inhabitants have an aversion to unequal provision of specific goods and services across jurisdictions. The provision of these goods or services in one jurisdiction has an impact on the welfare of others, bringing in a novel and important externality: each jurisdiction's choice of its own level of the publicly provided service alters the relative levels of the service across jurisdications, thereby impacting others' utilities because of people's aversion to inequality in the provision of the service. We analyze the strategic decisions of local and central governments and derive conclusions about the optimality of a centralized system, a decentralized system, and other forms of fiscal organization. Our perhaps surprising finding is that, when solidarity is present, a system whereby the central government provides a guaranteed minimum level of a publicly provided service and local governments can choose to add to this centrally-financed level performs significantly better than all other systems analyzed for the relevant range of parameters.

The paper proceeds as follows. In the next section we briefly summarize a selection of related studies that examine fiscal systems with multiple layers of government. In the third section, we characterize and evaluate the normative qualities of five stylized systems of fiscal federalism in a world where people have preferences for equality of provision of a set of goods and services that are the object of specific equalitarism, what we call solidarity. In the fourth section we simulate outcomes under the five systems, altering the preferences for solidarity from weak to strong and we rank the systems according to a measure of efficiency loss. We offer concluding remarks in the final section. 


\section{Related literature}

A number of authors have contributed to a rich literature on the efficiency gains and losses associated with fiscal decentralization. For example, Oates $(1972,1999)$ has argued there can be significant efficiency gains to having a federal system with fiscally empowered sub-national levels of government. In particular, a decentralized system can accommodate varying demands for public goods across regions. ${ }^{3}$ On the other hand, a decentralized system may not result in the optimal amount of income redistribution. Brown and Oates (1987), for example, explore the possibility that mobility of the poor across jurisdictions may thwart local attempts to redistribute income. In a model in which rich donors care only about the welfare of the nearby poor, Pauly (1973) presents a case for local redistribution of income. The tradeoffs arising from this literature between central provision and local provision of income redistribution revolve around the nature of preferences for redistribution and the extent of mobility of the rich and the poor across jurisdictions.

One fiscal federal system analysed below is a system whereby local or regional governments can make transfers among themselves. Interregional transfers arise in the work of Persson and Tabellini (1996) and Lockwood (1999). In these models the transfers are a means of sharing regional idiosyncratic risk and thus are efficiency enhancing.

A number of recent papers have been concerned with political economy aspects of fiscal federalism. Besley and Coate (2003) provide a model of the choice of the degree and nature of decentralization. They are interested in the inefficiencies created by the strategic behavior of locally elected representatives to a central legislature. Crémer and Palfrey (2000) examine the case of federal mandates, which operate much like federally guaranteed minimums (or maximums). They find that voters choose federal mandates that are too strict (required minimums that are inefficiently high). Alesina, Angeloni and Etro (2005) endogenize the size of a union of states and examine entry of new members, voting rules, and flexible policy arrangements, including federal mandates. Their analysis highlights the trade offs between the benefits and costs of policy coordination.

\footnotetext{
${ }^{3}$ See Oates's decentralization theorem (Oates, 1972, page 35).
} 
Our contribution to the literature is that we seek the most efficient federal system in a world where people have preferences for solidarity. To our knowledge we are the first to introduce Tobin's idea of specific egalitarianism into a fiscal system with multiple levels of government. We operationalize this solidarity concept as aversion to variance in the provision of publicly provided goods and services across regions and, recognizing that solidarity is itself a pure public good, we evaluate the efficiency performance of a number of familiar fiscal federal systems in a world with solidarity preferences. In doing so, we provide a new rationale for a system with a guaranteed minimum level of provision of (or fully-funded federal mandate for) the publicly provided good.

\section{A theory of fiscal decentralization with regional solidarity}

We specify a model with a central government and $n$ regional governments. Let region $i$ have initial wealth $\omega_{i}$ and $\Omega=\sum_{j=1}^{n} \omega_{j}$ represent aggregate wealth. There are two commodities: a privately provided good, $c_{i}$, and a publicly provided good, $g_{i}$. Both goods are private goods in that consumption is rival and excludable. The publicly provided good is an aggregate of all private goods for which, following Tobin's terminology, the domain of inequality is restricted (Tobin, 1970).

We assume that all regions are concerned with inequalities in the provision of the publicly provided good across regions and we measure inequality in provision by the variance ${ }^{4}$

$$
e=\frac{1}{n} \sum_{j=1}^{n}\left(g_{j}-\bar{g}\right)^{2} \quad \text { where } \quad \bar{g}=\frac{1}{n} \sum_{j=1}^{n} g_{j}
$$

Preferences of the $i$-th region are represented by a concave utility function $u_{i}\left(c_{i}, g_{i}, e\right)$, where

$$
\frac{\partial u_{i}}{\partial c_{i}}>0 \quad \frac{\partial u_{i}}{\partial g_{i}}>0 \quad \frac{\partial u_{i}}{\partial e}<0
$$

The sign of $\partial e / \partial g_{j}$ is positive or negative depending on whether the $j$-th region's public

\footnotetext{
${ }^{4}$ Garcia-Milà and McGuire (2004) introduce this formalization of inequality in the public provision of certain goods and services across regions, what the authors call solidarity. The authors argue that preferences over equality in provision of publicly provided goods might stem from a desire to bring or hold a country together after an upheaval or from a desire to provide access to essential public goods to all residents of the country.
} 
consumption is above or below the average public consumption. Hence, because utility is decreasing in $e$, an increase in public consumption by a region generates negative or positive externalities depending on its relative position with respect to the average. ${ }^{5}$

Support for preferences reflecting a concern for justice or equity, both in surveys and experimental work, is well established (see Konow, 2003, for a comprehensive discussion of the literature on justice). Alesina, Di Tella and MacCulloch (2004) examine the idea that preferences over inequality are important and may differ between the U.S. and and the twelve countries that composed the European Union through 1994. They find that individuals report to be less happy in the presence of inequality and that the European dislike of inequality is stronger than the American.

In order to gauge the performance of various fiscal federal systems we need first to characterize a Pareto optimal solution for the $n$ regions. If the allocation $\left(\tilde{c}_{j}, \tilde{g}_{j}\right)_{j=1}^{n}$ is Pareto optimal, then for any $i \in\{1,2, \ldots, n\}$ it is a solution to the problem:

$$
\begin{gathered}
\max \quad u_{i}\left(c_{i}, g_{i}, e\right) \\
\text { s.t. } u_{j}\left(c_{j}, g_{j}, e\right) \geq u_{j}\left(\tilde{c}_{j}, \tilde{g}_{j}, \tilde{e}\right) \quad j \neq i \\
\sum_{j=1}^{n} c_{j}+\sum_{j=1}^{n} g_{j}=\sum_{j=1}^{n} \omega_{j} \\
c_{i} \geq 0 \quad i \in\{1,2, \ldots, n\} \\
g_{i} \geq 0 \quad i \in\{1,2, \ldots, n\}
\end{gathered}
$$

The first order necessary conditions for this problem are therefore necessary conditions for Pareto-optimality.

The Lagrangian expression for this problem is

$$
L\left(c_{1}, c_{2}, \ldots, c_{n}, g_{1}, g_{2}, \ldots, g_{n}, \lambda\right)=u_{i}\left(c_{i}, g_{i}, e\right)+\sum_{j \neq i}^{n} \alpha_{j}\left(u_{j}\left(c_{j}, g_{j}, e\right)-u_{j}\left(\tilde{c}_{j}, \tilde{g}_{j}, \tilde{e}\right)\right)-\lambda\left(\sum_{j=1}^{n}\left(c_{j}+g_{j}\right)-\sum_{j=1}^{n} \omega_{j}\right)
$$

and since constant terms can be ignored it can be written as

\footnotetext{
${ }^{5}$ While variance accords well with Tobin's idea of egalitarianism, it potentially violates monotonicity of preferences in that an extra unit of the public good helicopter-dropped on a high-wealth region could potentially result in a decrease in utility.
} 


$$
L\left(c_{1}, c_{2}, \ldots, c_{n}, g_{1}, g_{2}, \ldots, g_{n}, \lambda\right)=\sum_{j=1}^{n} \alpha_{j} u_{j}\left(c_{j}, g_{j}, e\right)-\lambda\left(\sum_{j=1}^{n}\left(c_{j}+g_{j}\right)-\sum_{j=1}^{n} \omega_{j}\right)
$$

with $\alpha_{i}=1$. The Kuhn-Tucker first order necessary conditions are:

$$
\begin{array}{ll}
\frac{\partial L}{\partial c_{i}}=\alpha_{i} \frac{\partial u_{i}}{\partial c_{i}}-\lambda \leq 0 & i \in\{1,2, \ldots, n\} \\
\frac{\partial L}{\partial g_{i}}=\alpha_{i} \frac{\partial u_{i}}{\partial g_{i}}+\sum_{j=1}^{n} \alpha_{j} \frac{\partial u_{j}}{\partial e} \frac{\partial e}{\partial g_{i}}-\lambda \leq 0 & i \in\{1,2, \ldots, n\}
\end{array}
$$

In the case of interior solutions, each of these inequalities must hold with equality and, for any pair of regions $i, j$, the following equalities must hold

$$
\begin{aligned}
\alpha_{i} \frac{\partial u_{i}}{\partial c_{i}} & =\alpha_{j} \frac{\partial u_{j}}{\partial c_{j}} \forall i, j \\
\alpha_{i} \frac{\partial u_{i}}{\partial g_{i}}+\frac{2}{n}\left(g_{i}-\bar{g}\right) \sum_{k=1}^{n} \alpha_{k} \frac{\partial u_{k}}{\partial e} & =\alpha_{j} \frac{\partial u_{j}}{\partial g_{j}}+\frac{2}{n}\left(g_{j}-\bar{g}\right) \sum_{k=1}^{n} \alpha_{k} \frac{\partial u_{k}}{\partial e} \forall i, j \\
\alpha_{i} \frac{\partial u_{i}}{\partial c_{i}} & =\alpha_{j} \frac{\partial u_{j}}{\partial g_{j}}+\frac{2}{n}\left(g_{j}-\bar{g}\right) \sum_{k=1}^{n} \alpha_{k} \frac{\partial u_{k}}{\partial e} \forall i, j
\end{aligned}
$$

where the derivative $\frac{\partial e}{\partial g_{i}}$, measuring the impact of the publicly provided good on the inequality index, is $\frac{1}{n}\left(2\left(g_{i}-\bar{g}\right)\left(1-\frac{1}{n}\right)+\sum_{j=i} 2\left(g_{j}-\bar{g}\right)\left(-\frac{1}{n}\right)\right)$, which simplifies to $\frac{2}{n}\left(g_{i}-\bar{g}\right)$.

Equation (8) requires that the marginal contribution of the privately provided good to social welfare be the same in all regions. Equation (9) requires the equality of the marginal contributions of the publicly provided good to social welfare in all regions. Finally, equation (10) establishes that the marginal contribution to social welfare of the privately provided good equals that of the publicly provided good in all regions.

As can be seen in (9) and (10), the marginal contribution to social welfare of the publicly provided good in a given region $i$ has two components: the direct effect, $\alpha_{i} \frac{\partial u_{i}}{\partial g_{i}}$, and the indirect effect of $g_{i}$ on all regions' welfare through $e$

$$
\frac{2}{n}\left(g_{i}-\bar{g}\right) \sum_{k=1}^{n} \alpha_{k} \frac{\partial u_{k}}{\partial e}
$$

The indirect effect reflects the public-good nature of $e$ when region $i$ alters its level of $g_{i}$ it 
impacts $e$ and results in spillover benefits or costs for other regions. If the provision of publicly provided goods across regions is equalized, then $g_{i}=\bar{g}$ and the indirect effect disappears.

We consider five different, commonly explored, fiscal systems. In each there is a central government and $n$ regional governments.

a. Centralization: In this model, the central government imposes a uniform tax rate to raise funds for provision of a uniform level of the publicly provided good across regions in the country. ${ }^{6}$ There is a continuum of possible allocations as the tax rate varies from zero to one. Intergovernmental grants from the central government to the regions are the sole source of funding for expenditures on the publicly provided good. Regional governments are essentially administrative arms of the central government; they make no decisions.

b. Decentralization: In this model, regional governments have taxing authority and are solely responsible for raising revenues. They are free to set the level of the publicly provided good without any interference (or assistance) from the central government. The central government makes no decisions and for all practical purposes is immaterial. Regions are aware of the interdependence of their decisions and act accordingly.

c. Voluntary transfers: Regional governments have taxing authority and are solely responsible for raising revenues. They can choose to make voluntary transfers to other regional governments to help the other regions increase spending on the publicly provided good. In doing so, they take into account the decisions of all other regions. There is no role for the central government.

d. Guaranteed minimum: The central government imposes a uniform tax rate, which can take values from zero to one. The tax revenues are used to fund a central grant to regions. This central grant supports a uniform minimal (adequate) level of the publicly provided good in each region. Regions have local taxing authority that they can employ to adjust the

\footnotetext{
${ }^{6}$ Uniform taxation and uniform provision under centralization is a stylized assumption. Uniform provision is challenged by Besley and Coate (2003), for example. We employ the uniformity assumption here in part to provide a stark contrast with other systems and in part because it is a not implausible system due to information and political constraints. In addition, our focus on a concern for equality makes it natural to posit a common tax function and undifferentiated levels of the publicly provided good for the centralized system. Finally, these assumptions provide easy comparison with much of the literature and, in particular, with the work of Oates.
} 
spending levels above the minimum level financed by the central government. This decision is taken while considering the choices of the other regions.

e. Matching grants: The central government provides a matching grant whereby each dollar of spending by the regional governments is subsidized at the matching rate. The matching rate can be any non-negative number. Regional governments choose the level of spending taking into account the matching rate and the decisions of all other regions.

In Appendix A we show that the solution to each of theses systems is characterized by a set of conditions that differ from the conditions for a Pareto optimal allocation (equations 8-10). In the case of centralization, in which uniformity in public good provision is imposed by the central government, the inefficiency arises from utility losses associated with this uniformity. Under decentralization, voluntary transfers, guaranteed minimum, and matching grants, regions have the authority to adjust at the margin the level of their own publicly provided good. These adjustments generate externalities associated with local provision of the public good solidarity; regions do not take into account the impact of their choices of the publicly provided good on other regions' utilities, which is required for a Pareto optimum (equation 10).

We have learned from the theoretical results that when solidarity is present all the systems analyzed are inefficient. This is as far as we can go with theoretical analysis. What is interesting, and that we are only able to establish through simulations presented in the next section, is that there are significant and systematic differences in the efficiency losses of the different systems.

\section{Simulation results}

The complexity introduced into the model by solidarity preferences makes it difficult to obtain closed-form solutions. To get a deeper understanding of how well each of these systems performs and to compare their relative performances we turn to simulations. Our goal is to characterize the relationship between the strength of solidarity preferences and the best choice for the fiscal federal system.

We consider a simple multilevel-government system consisting of two types of regions, "rich" and "poor". This allows for a clear two-dimensional graphical representation of the results. In order to analyze the effect of the size of the federation independently of that of preferences 
and endowments, we consider $n$-replicas of the simple system, that is, a multilevel government with $n$ identical local governments of each type. ${ }^{7}$ The rich regions have wealth $\omega_{r}=80$, and the poor regions have wealth $\omega_{p}=20$. We represent preferences by modified Cobb-Douglas utility functions:

$$
\begin{array}{ll}
u\left(c_{r}, g_{r}, e\right)=K c_{r}^{\alpha} g_{r}^{1-\alpha} \frac{1000}{1000+\gamma e} & \text { for the rich regions, } \\
u\left(c_{p}, g_{p}, e\right)=K c_{p}^{1-\alpha} g_{p}^{\alpha} \frac{1000}{1000+\gamma e} \quad \text { for the poor regions. }
\end{array}
$$

where $c_{i} \geq 0, g_{i} \geq 0$ and $e$ is the variance across regions of the publicly provided goods. For the simulations that follow we fix $n=2, K=10$, and $\alpha=\frac{1}{4}{ }^{8}$

The parameter $\gamma$ is a nonnegative number capturing the strength of the solidarity preferences. When $\gamma=0$, preferences for solidarity are nonexistent; as $\gamma$ increases, preferences for solidarity intensify. The variable $e$ takes value zero if provision is equalized; otherwise it is strictly positive. To clarify the nature of the class of utility functions, decompose the utility function into two parts: the standard utility, $K c_{i}^{\beta} g_{i}^{\delta}$, representing preferences between the privately provided good and the publicly provided good, and the solidarity effect, $\frac{1000}{1000+\gamma e}$. When there is no inequality, or preferences for solidarity are nonexistent, the solidarity effect takes its maximum value of one and, in that case, total utility coincides with the standard utility. When there is inequality (the variance $e$ is positive) and people have preferences over solidarity, the solidarity effect is less than one and total utility is less than the standard utility. The solidarity effect, and therefore utility, tends to zero as the variance $e$ grows to infinity (assuming $\gamma>0$ ).

Because the two regions of a given type are identical, their optimal choices will be the same. Therefore we can characterize solutions in a two dimensional graph, with one dimension representing the utility of a rich region and the other dimension the utility of a poor region. We

\footnotetext{
${ }^{7}$ This idea of $n$-replicas was introduced by Debreu and Scarf (1963) when they generalized Edgeworth's famous result about the shrinking of the contract curve towards the competitive allocation as the size of the economy becomes large.

${ }^{8}$ Our simulation results are qualitatively the same for various values of the parameter $\alpha$, including when preferences are identical $(\alpha=1 / 2)$. We have also performed simulations with identical Stone-Geary utility functions, with no major changes in the simulation results and conclusions.
} 
illustrate the performance of the various fiscal systems relative to the set of Pareto optimal utility allocations, which are represented on the graphs by the utility frontier. We do not postulate a social welfare function for the central government and, therefore, when the central government is involved there is not a unique solution but rather a locus of attainable allocations for each central tax rate. For each simulation we derive either the unique point in the cases of decentralization and voluntary transfers or the locus of possible allocations in the cases of centralization, guaranteed minimum, and matching grants.

We examine graphically five situations that differ in terms of the strength of preferences for solidarity, as parametrized by $\gamma$. To get an intuitive measure of the degree of solidarity preferences, we associate each value of $\gamma$ to a transformation $\mu$ that gives the percentage loss in utility at a fixed variance $\bar{e}$, where $\bar{e}$ is the variance that obtains when preferences for solidarity are nonexistent and regions optimally choose government expenditures. ${ }^{9}$ As $\gamma$ varies from zero to infinity (and preferences for solidarity become increasingly strong), $\mu$ takes values between zero and 100 percent. We choose values for $\gamma$ that correspond to utility losses (evaluated at the point where regions consume government expenditures associated with $\bar{e}$ ) equal to $0,10,25,40$ and 50 percent. We consider 50 percent to be the upper bound of reasonable preferences as it represents the case where the degree of preferences for solidarity is such that an individual cares about the utility of others as much as he cares about his own utility. We consider values of $\mu$ beyond 50 percent to be unrealistic.

To gauge the performance of each fiscal system, we calculate a precise measure of the efficiency loss associated with each system. The efficiency loss of a given allocation is the amount of resources wasted by the allocation in attaining its utility levels compared with the minimal resources necessary to attain those same utility levels, where the amount of wasted resources is expressed as a percentage. So, for example, if an allocation uses 100 units of resources to achieve a vector of utility levels and a benevolent dictator could achieve the same utlity levels for the regions while using 80 units, then our measure of efficiency loss would be 20 percent. For a given fiscal system the efficiency loss is the minimum of the efficiency losses of all allocations attainable under that system. A lower value of the efficiency loss measure

${ }^{9}$ The transformation is $\mu=\left(1-\frac{1000}{1000+\gamma \bar{e}}\right) \times 100$. 
represents a better performing system. ${ }^{10}$

We begin with the situation in which regions do not have a preference for solidarity $(\gamma=0$ and $\mu$ is 0 percent). In this case the utility function reverts back to the standard Cobb-Douglas utility function. In Figure 1 we represent the utility levels attained under the five different systems. The horizontal axis represents the utility level of the rich regions, and the vertical axis the utility level of the poor regions. The decentralization solution D and the voluntary transfers solution $\mathrm{V}$ are identical -- $\mathrm{V}$ is equal to $\mathrm{D}$ because the optimal choice of voluntary transfers is zero when solidarity preferences are nonexistent -- and the solution lies on the utility possibility frontier. The result that $\mathrm{D}$ lies on the frontier is a finding of the standard theory of fiscal decentralization: if all goods are private and demands vary across regions, the decentralized solution is optimal.

The locus of possible allocations under a centralized system is represented by the solid, elliptical line. We find it useful to take as references two particular points on the locus: P, where, in the Rawlsian tradition, the utility of the poor regions is maximized; and $\mathrm{R}$, the allocation that maximizes the utility of the rich regions. We consider the set of allocations between $\mathrm{P}$ and $\mathrm{R}$ to be the relevant set because they are not "second best" Pareto dominated. These allocations fall far short of the utility frontier, illustrating the rigidities generated by the uniformities of the centralized system.

Under the matching grant, when the matching rate is zero, the allocation is equal to the decentralization allocation. As the matching rate increases from zero, the allocations move away from the utility frontier along the locus of dashes. This is the case because the resources raised by the central government are used to subsidize government expenditures of the regions, with a larger transfer for regions that choose larger government expenditures, the rich in our setup. Poor regions lose with the matching grant, and, with no solidarity, there is no gain in moving away from the decentralized allocation.

\footnotetext{
${ }^{10}$ See Appendix B for a formal definition of the efficiency loss measure.
} 


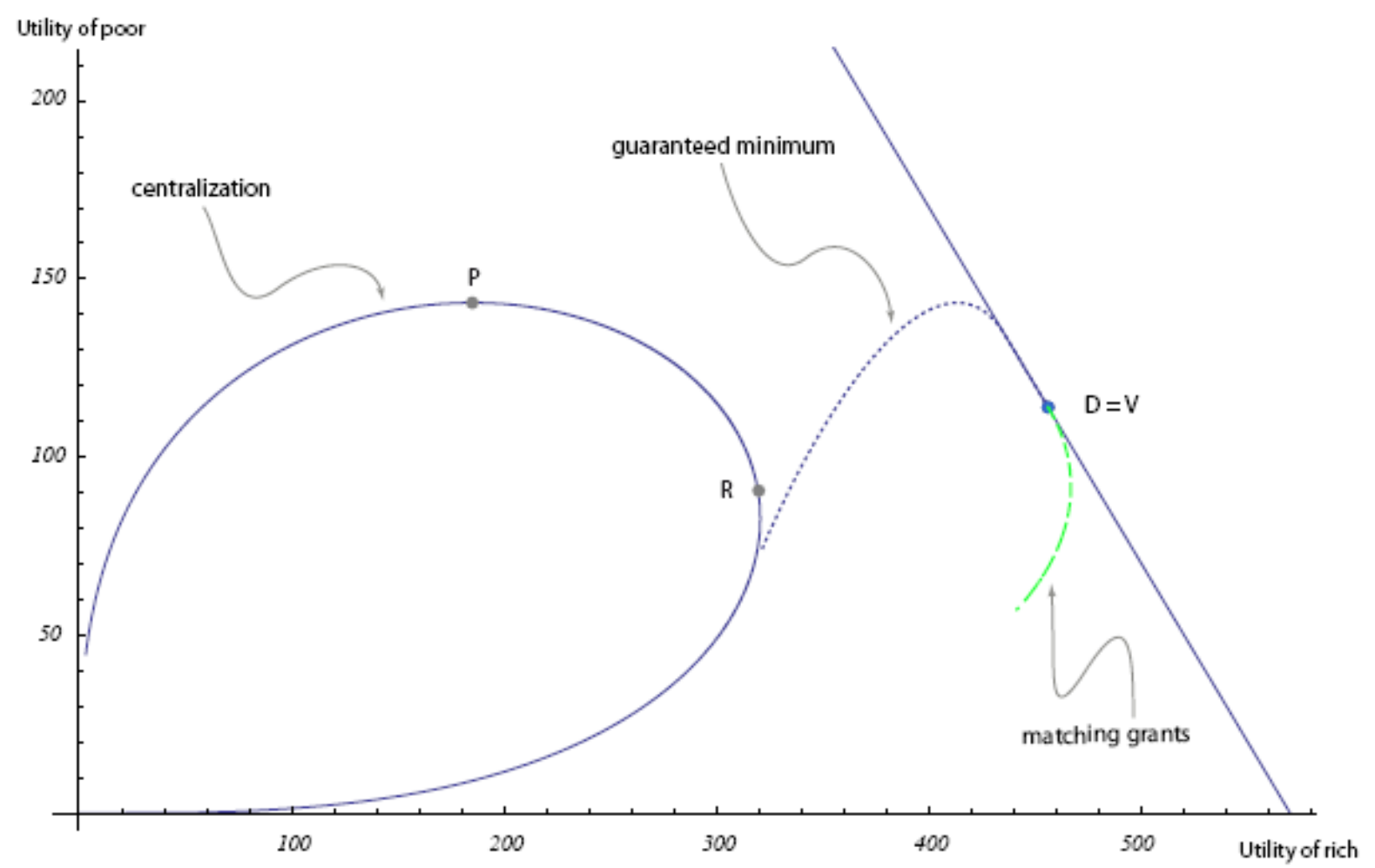

Figure 1: Utility allocations with no taste for solidarity

Finally, under a guaranteed minimum system, the locus of possible allocations is represented by the dotted line. When the central tax rate is zero, the allocation is at point $\mathrm{D}$ (equal to $\mathrm{V}$ ) on the utility frontier. As the central government increases its tax rate, we move along the dotted line. If the centrally provided minimum level is not too high and all four regions choose positive amounts of additional publicly provided good to add to the guaranteed minimum amount, then the locus is on the frontier. This can easily be seen by checking that, in this case, where solidarity preferences do not exist (and thus $\frac{\partial u}{\partial e}=0$ ), the necessary conditions for an interior solution are also sufficient for Pareto optimality (compare equations (8)-(10) above with (38) in Appendix A). When the centrally provided minimum level becomes sufficiently high, the locus approaches and ultimately joins the centralization locus. 
For all systems except centralization, the efficiency loss is zero because the maximum utility levels achievable under these systems are on the utility frontier. For the centralization system, the best possible allocation has an efficiency loss value of 26.915 percent, meaning that the best allocation attainable under centralization could be attained by a benevolent dictator using 26.915 percent fewer resources. Thus, when preferences for solidarity are nonexistent, the centralization system is outperformed by the other systems. This result is not surprising: without solidarity preferences, centralization offers no gains in utlity because people do not care about disparities in public good provision.

Consider now the situation where preferences for solidarity are weak $(\gamma=0.204$ and $\mu$ is 10 percent). Figure 2 illustrates the possible allocations under all five systems. When preferences for solidarity are non-zero, there are no allocations on the utility frontier. The decentralization allocation is still equal to the voluntary transfers allocation (voluntary transfers are still zero) because the concern for solidarity is not strong enough to overcome the concern that other regions will free ride on a given region's generosity. Now, in the presence of solidarity preferences, the decentralized allocation is outperformed by a portion of the guaranteed minimum locus. This occurs because the guaranteed minumum system enables the regions to reduce inequality without the prospect of free riding. The relevant range of the centralization locus remains far from the utility frontier and it is outperformed by allocations under each of the other systems.

We quantify the relative performance of the five systems using the efficiency loss measure. The best allocation under centralization results in an efficiency loss of 21.902 percent, implying that the allocation could be achieved using 21.902 percent fewer resources. This efficiency loss is much larger than the losses under the other systems. The efficiency loss associated with decentralization, voluntary transfers, and the best allocation under matching grants is 1.320 percent. The best allocation under the guaranteed minimum system results in an efficiency loss of only 0.457 percent, about one-third the loss under decentralization and less than one-fortieth the loss under centralization. The four systems allowing for local choice perform well in this case because the utility losses associated with unequal provision of the public good are small when preferences for solidarity are weak. 


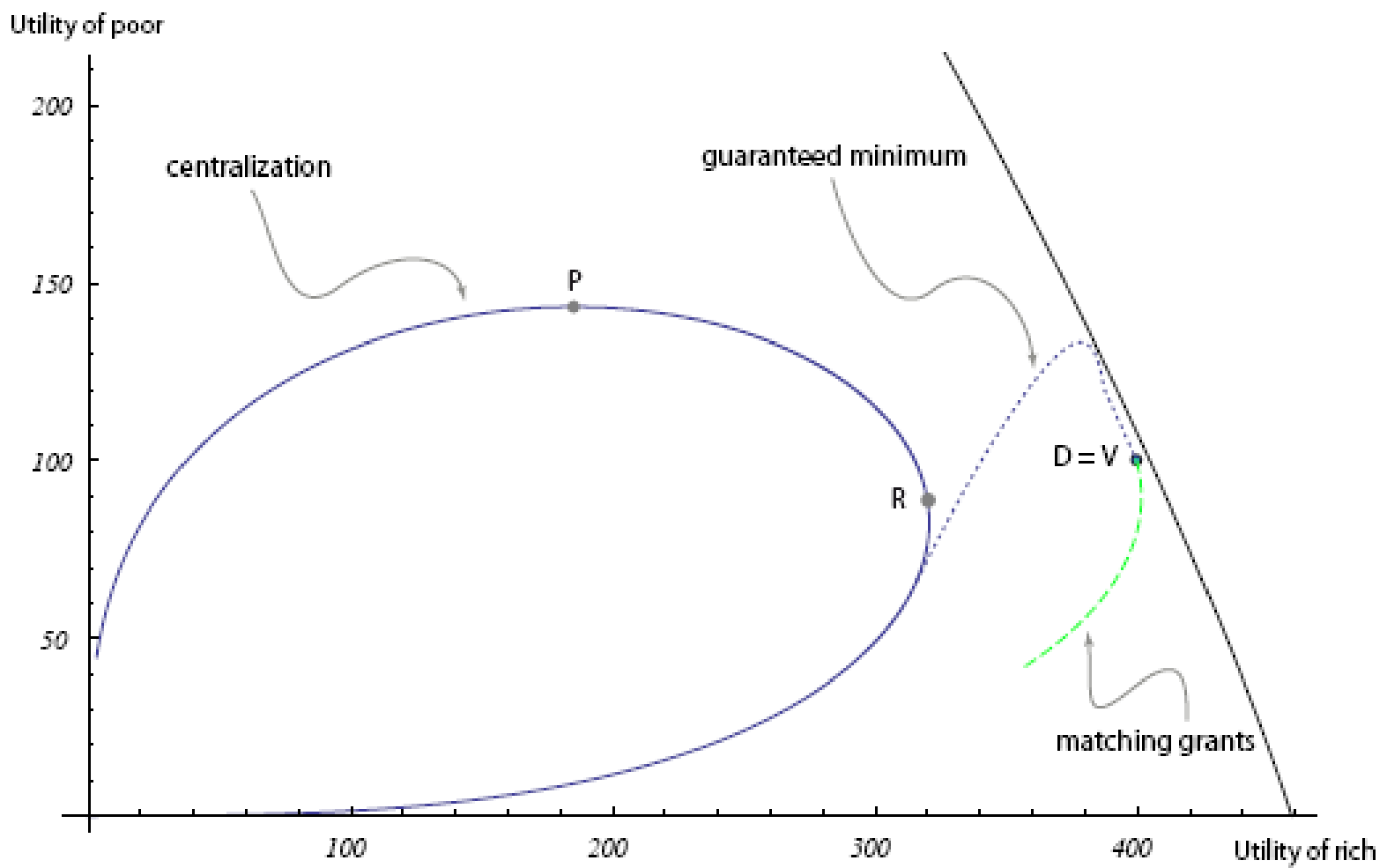

Figure 2: Utility allocations with weak preferences for solidarity

In Figure 3, we illustrate the possible allocations for each fiscal federal system when preferences for solidarity are moderately strong $(\gamma=0.612$ and $\mu$ is 25 percent). The shape of the guaranteed minimum locus illustrates well the intuition of this model. For low guaranteed values of the public good, poor regions improve their utility as they receive a subsidy for the level they would have chosen on their own. As the guaranteed minimun value increases and reaches a value higher than the decentralized choice for the poor, the variance diminishes and both poor and rich improve their utility levels and the locus bends to the right. But, eventually, the guaranteed minimum is too high and the resources allocated to the public good would be better used in private consumption, therefore the locus moves to the southwest eventually merging with the centralization locus.

The decentralization allocation continues to be equal to the voluntary transfers allocation 
(voluntary transfers continue to be zero), but the allocation is quite far from the utility frontier, with an efficiency loss of 9.220 percent. The best allocation under the guaranteed minimum system is much closer to the utility frontier than is the decentralization allocation, with an efficiency loss nearly nine times smaller (at 1.084 percent). With moderately strong solidarity preferences, centralization performs relatively well: its efficiency loss is 12.859 percent, still the largest efficiency loss of all of the systems, but only half again as large as the efficiency loss under decentralization.

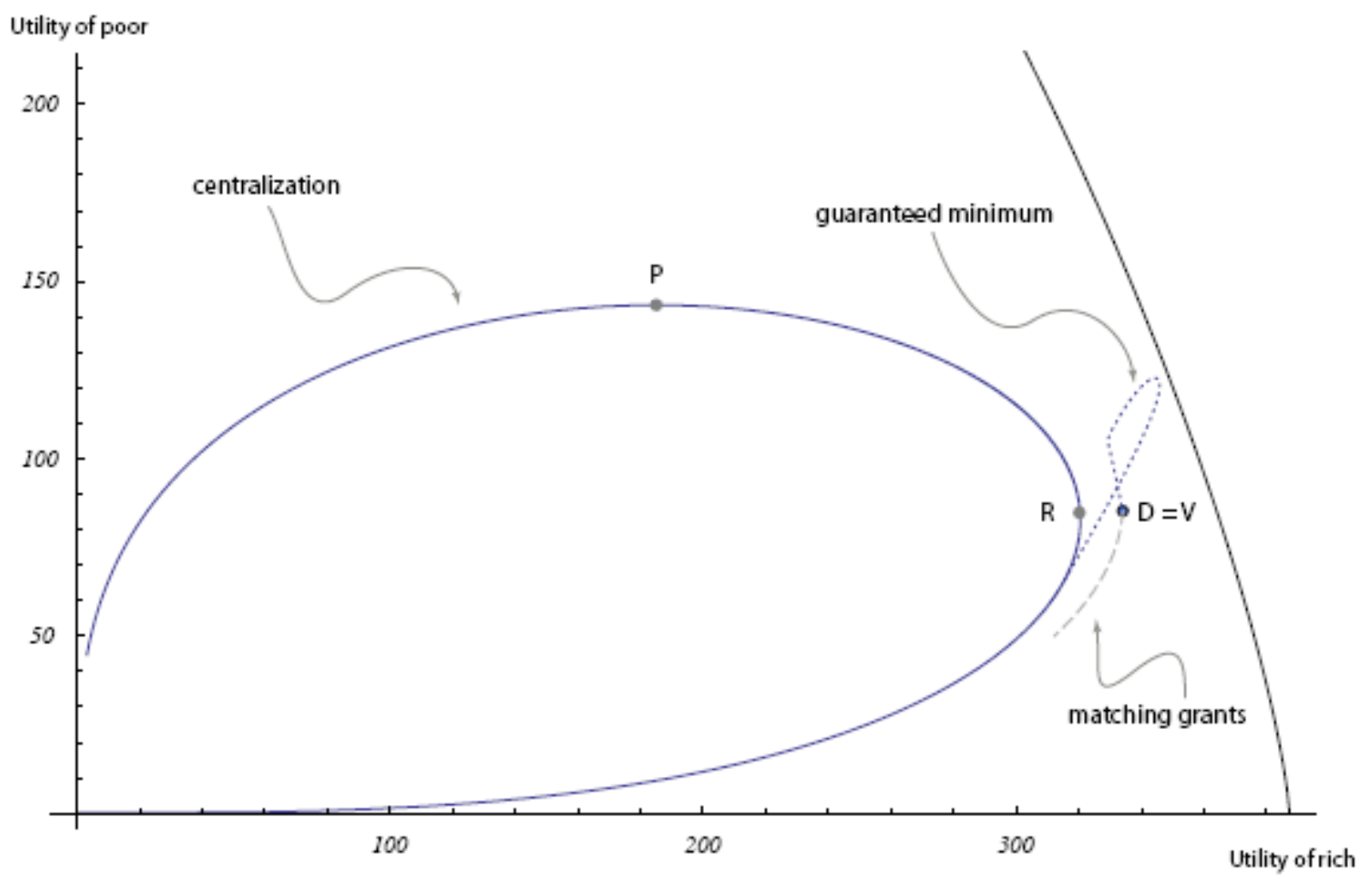

Figure 3: Utility allocations with moderately strong preferences for solidarity

Preferences for solidarity are strong in Figure $4(\gamma=1.224$ and $\mu$ is 40 percent). The allocations under decentralization and voluntary transfers are now distinct from one another. Voluntary transfers are positive because when solidarity is strong enough, the gain in utility that results from reducing the variance dominates the free-rider costs borne by the rich regions . Both 
allocations are inside the locus of centralization allocations. Centralization now performs much better because the gains of having zero variance under centralization outweigh the costs of imposing a uniform public provision . The guaranteed minimum system continues to outperform the centralization system, with a large portion of its locus being much closer to the utility frontier than the centralization locus, but the relative performances of the two systems are now much closer: the efficiency loss of the guaranteed minimum system is 1.123 percent and the efficiency loss of centralization is 6.994 percent. The other three systems perform relatively poorly when solidarity preferences are strong, with efficiency losses of 20.026 percent for decentralization and matching grants and 18.163 percent for voluntary transfers.

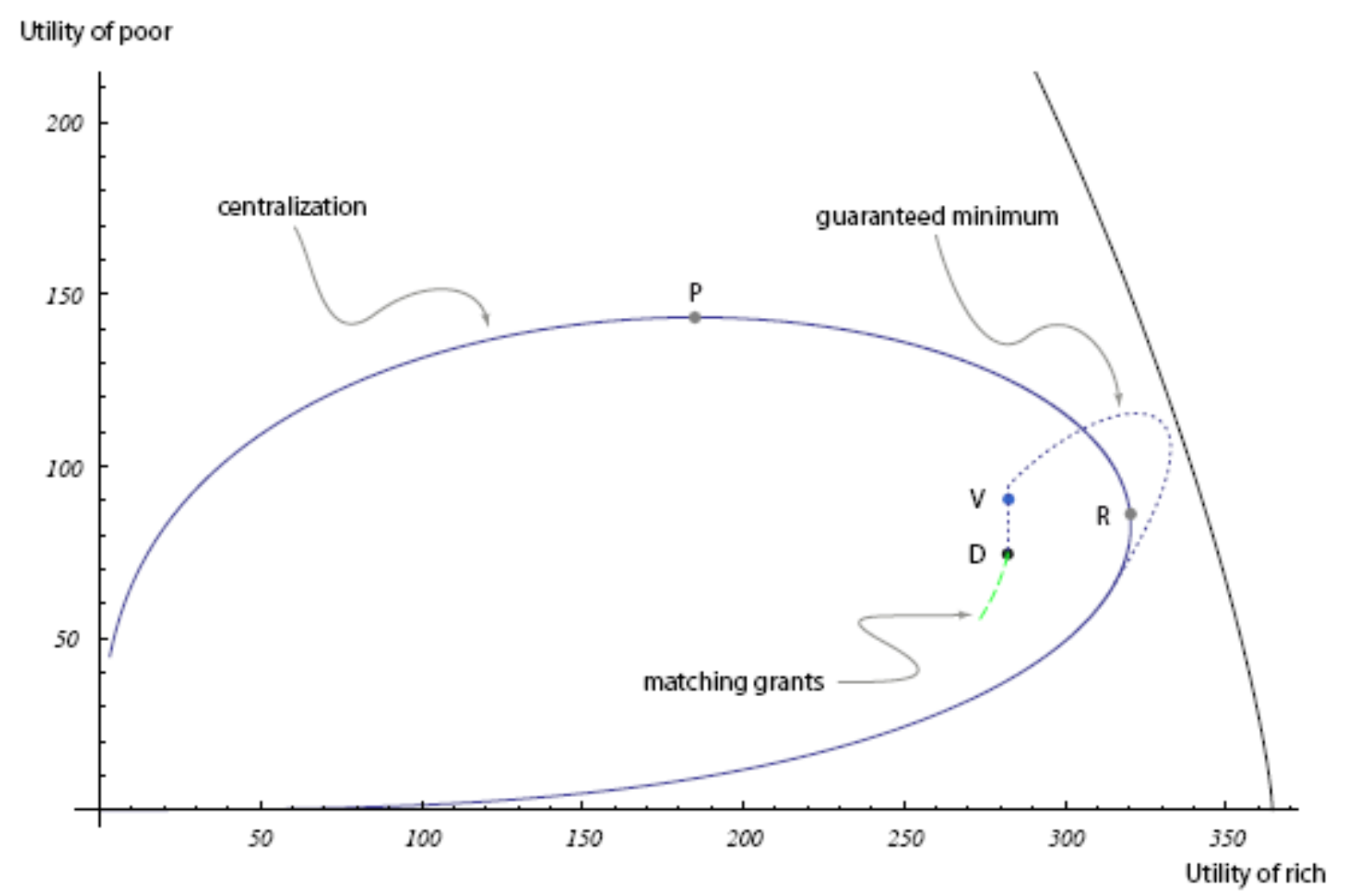

Figure 4: Utility allocations with strong preferences for solidarity

Finally, in Figure 5 we illustrate the extreme case where preferences for solidarity are exceedingly strong $(\gamma=2.755$ and $\mu$ is 50 percent). The system of voluntary transfers now performs much better than decentralization (and matching grants) - the efficiency losses are 
14.226 percent for voluntary transfers and 27.095 percent for decentralization. With such strong solidarity preferences, there is a large benefit derived from reducing the variance that is attained by increasing the public provision of the public good in the poor regions with transfers from the rich regions. The guaranteed minimum system continues to outperform all other systems (efficiency loss of 1.075), with centralization not far behind (efficiency loss of 4.740). Both of these systems perform quite well when preferences for solidarity are exceedingly strong.

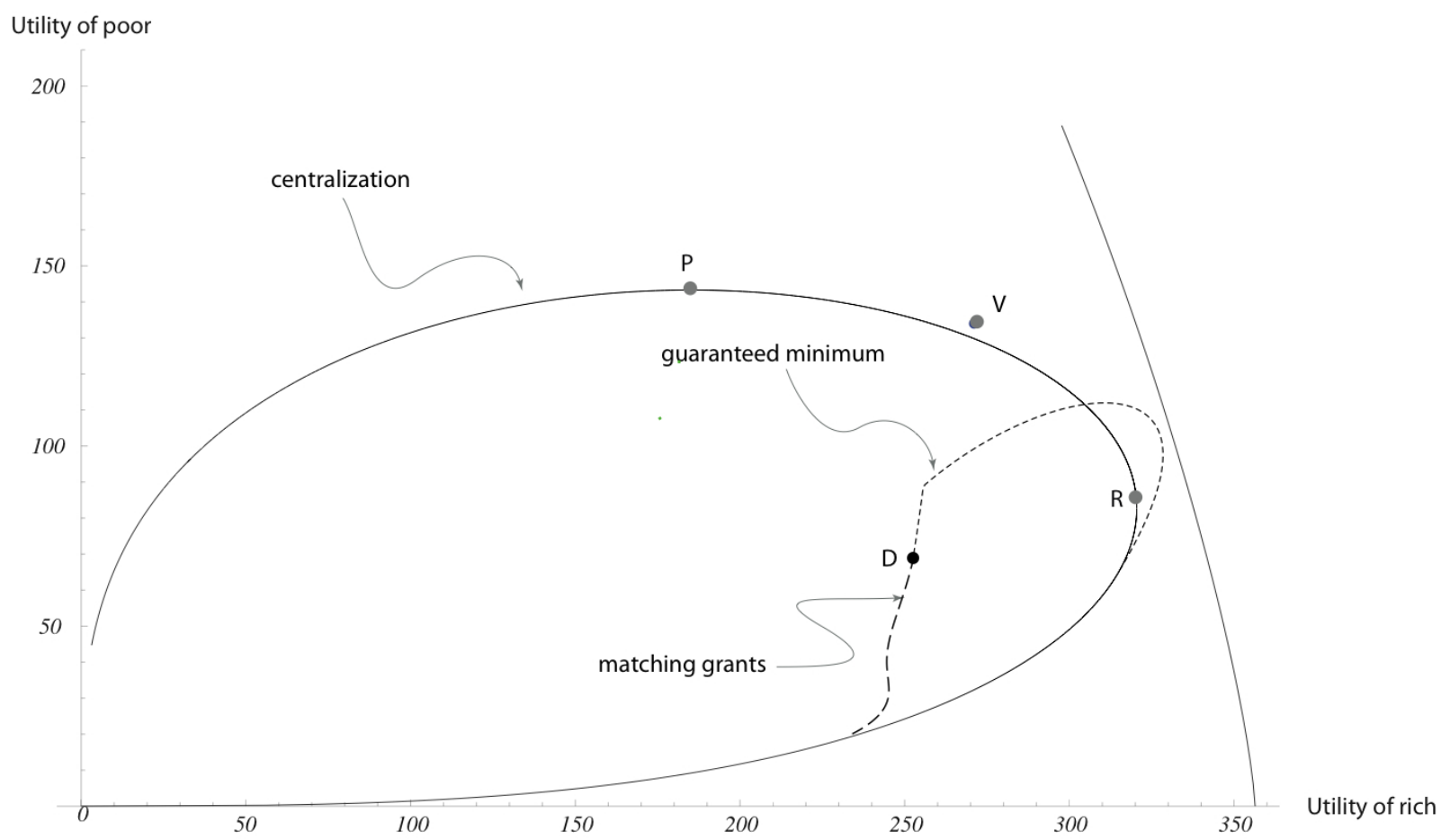

Figure 5: Utility allocations with very strong preferences for solidarity

In Figure 6 we present the values of the efficiency loss for the five systems analyzed for continous values of $\gamma$, represented in the horizontal axis by its transformation $\mu$. (As the efficiency loss of matching grants is always equal to the efficiency loss of decentralization, we label the common curve decentralization.) We can see that as preferences for solidarity increase in intensity (as $\mu$ increases) the efficiency loss decreases for the centralized system and increases for decentralization (and matching grants). The efficiency loss for voluntary transfers is relatively 
low for a range of values of the solidarity preference parameter, but there is always a guaranteed minimum solution that attains a lower efficiency loss than any of the other systems. Thus, a guaranteed minimum system outpeforms all other systems as long as solidarity preferences are non-zero. We obtain this result because the guaranteed minimum system has the capacity to improve upon centralization as it allows for local variation. The guaranteed minimum system also impoves upon the allocations resulting from the other three versions of decentralized decisionmaking because it directly addresses inequality in spending across regions by providing a common floor for regional spending. Further, the guaranteed minimum system blunts the freerider problem inherent in decentralized systems by requiring a certain and equal amount of provision of the publicly provided good in all regions. ${ }^{11}$

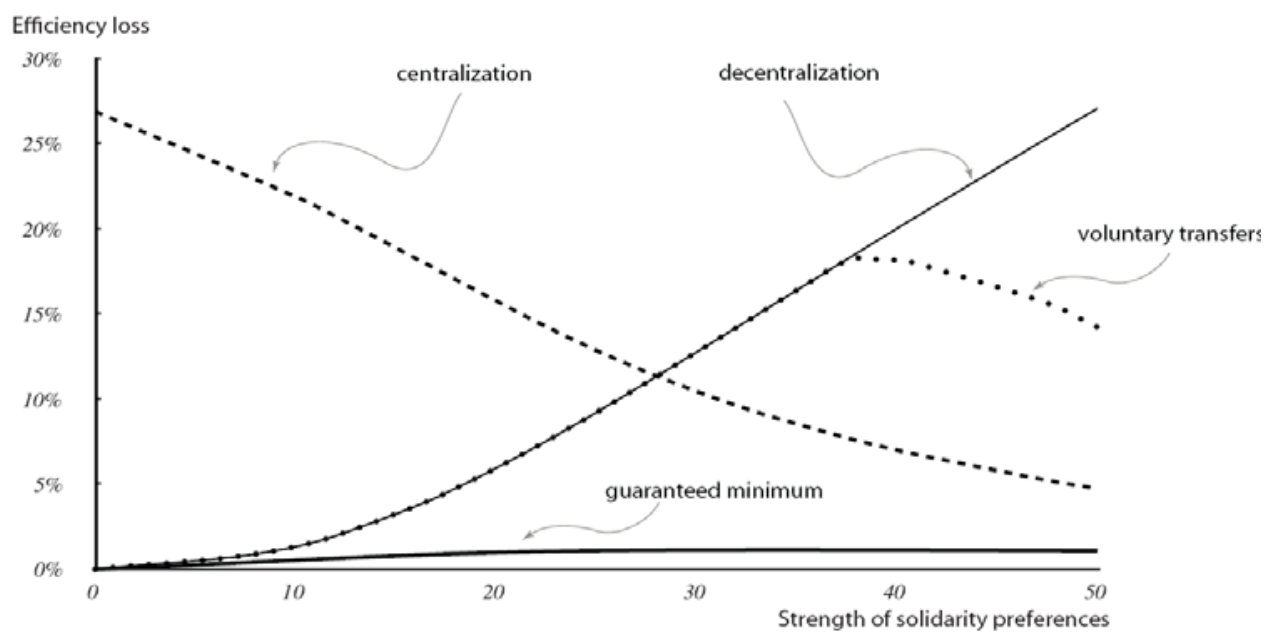

Figure 6 : Efficiency loss associated with varying tastes for solidarity

The simulation results presented so far are obtained for 2-replicas of our basic economy, that is, for multilevel systems with four local governments, two of each type. In Figure 7 we explore how varying the number of replicas modifies the results. While the efficiency-loss curve

\footnotetext{
${ }^{11}$ Others have arrived at the guaranteed minimum system, but have done so with models that in essence override local preferences. For example, Musgrave and Musgrave (1989) discuss the national objective of ensuring minimum levels of provision for merit goods. Gramlich (1985) examines the decentralized setting of cash welfare benefits in the 50 U.S. states. His analysis leads him to take a "somewhat paternalistic position" (page 43) in which he advocates for a federally guaranteed minimum level, with optional state supplementation. His point is that, without the federally-financed minimum level, state governments, acting on their preferences, will choose benefit levels that are not high enough to raise families out of poverty. Our approach is very different in that the guaranteed minimum system arises from local preferences as a means of overcoming market failures associated with the public good solidarity.
} 
corresponding to centralization does not change, the decentralization, voluntary transfers, and guaranteed minimum systems become more inefficient as the number of local governments increases.

It is interesting to note that while the voluntary transfers system is highly efficient for $n=1$, that is when there is only one region of each type, it loses efficiency rapidly as the size of the federation increases, converging to decentralization (because optimal voluntary transfers are zero) once replicas reach $n=3$.

The guaranteed minimum system performs, in efficiency terms, better than any of the other systems, and, although it deteriorates slightly as the number of regions increases, it dominates all other systems for any size of the federation. ${ }^{12}$

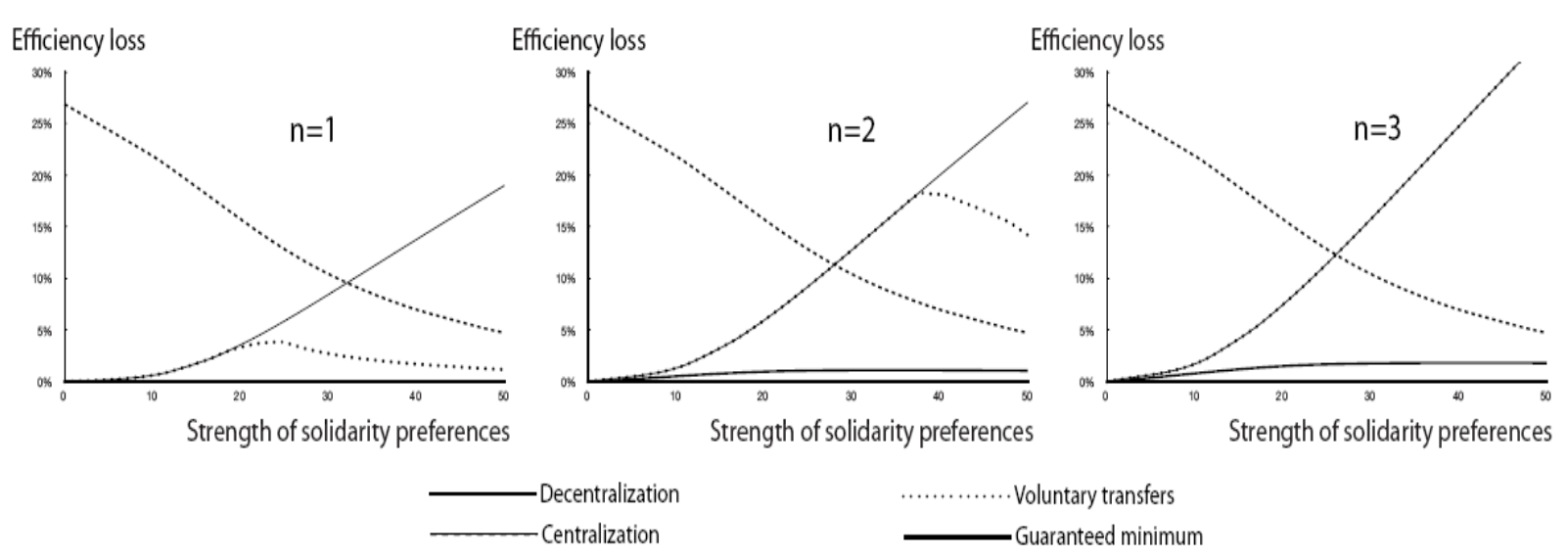

Figure 7 : Efficiency loss for increasing size of the federation

\section{Conclusion}

The contribution of this paper is to introduce into the classic treatment of fiscal federalism a new (to this setting) and, we believe, important aspect of public sector provision of goods and services - that people have a desire to distribute some goods and services, those that determine life chances, less unequally than people's abilities to pay for them. Our treatment of a concern for

\footnotetext{
${ }^{12}$ We have explored large federations, as large as $n=10,000$. Results do not change qualitatively from the ones presented for $n=$ 3 , and the dominance of the guaranteed minimum system prevails.
} 
equality differs from standard approaches in two respects. First, egalitarianism is not imposed from above: there is no central government social welfare function incorporating egalitarian principles. Rather, it is local regions that have a preference for solidarity. The central government's objective is to reach a Pareto-efficient allocation given these preferences. Second, as Tobin (1970) indicates, to the extent that economists are egalitarians at all, they are general egalitarians: if an unequal distribution of food and shelter is deemed undesirable economists tend to look to changing the distributions of wealth and income rather than food and shelter, as efforts at equalizing the consumption of specific commodities will inevitably generate inefficiencies. In this paper, we depart from the standard views and advocate Tobin's idea of specific egalitarianism. We model a concern for equality of opportunity as preferences for equality in the consumption of certain goods and services, such as education and health care, that are deemed to be essential to succeed in life. This is what we call solidarity.

Education and health care, even though they are private services by nature, are, in large part, provided by the public sector; in some countries they are provided by the central government, in others by local governments, and still in others the responsibility is shared among multiple levels of government. Arguably, Oates's decentralization theorem (Oates, 1972) would seem to point to local provision for these two services. We show that when people care about the distribution of these publicly provided goods, indeed, if they get disutility from there being an unequal distribution across regions, local provision will not be optimal. This is the case because equality in the provision of publicly provided goods (i.e., solidarity) is a pure public good and a decentralized system will not address the associated externalities and free-rider problems. Where preferences for solidarity are strong, as apparently they are in many European countries and with respect to education in many U.S. states, ${ }^{13}$ moving away from decentralized provision of publicly provided goods and services can increase social welfare.

We construct a very simple model of a federation in which solidarity preferences are the only potential source of market failure. Our main results are as follows.

Generalized inefficiency. In a very general setting we show that, in the presence of solidarity,

\footnotetext{
${ }^{13}$ Many U.S. states have language in their constitutions requiring some form of equalization of education across local school districts.
} 
all the systems analyzed are inefficient. Surprisingly, though, we find significant differences in the order of magnitude of the inefficiencies generated by alternative systems.

Centralization versus decentralization. The extent to which a centralized fiscal system outperforms a decentralized one depends upon the strength of solidarity preferences. However, we find that attention should not be restricted to the two polar cases of centralization and deccentralization; in between these two extremes there are systems that warrant further consideration.

The voluntary transfer system may only be appropriate for federations with a very small number of regional governments. Since our regional governments are specific egalitarianians in Tobin's sense, a decentralized system with the possibility of voluntary transfers seems a very natural option. In federations with very small numbers of regions it performs surprisingly well relative to both a centralized system and a system with full decentralization. Unfortunately, its performance deteriorates rapidly as the number of regions increases.

The superiority of the guaranteed minimum system. Our most notable finding is that, among several systems analyzed, one system appears to outperform all others for all reasonable values of the strength of preferences for solidarity. The guaranteed minimum system (equivalent to a fullyfunded federal mandate) outperforms the other systems including the polar systems of complete decentralization and complete centralization because it combines the externality internalizing aspects of centralization with the regional authority of a decentralized system to adjust spending levels in line with regional preferences. 


\section{APPENDIX A: Formal characterization of five fiscal federal systems}

\section{A.1 Centralization}

Under this system, taxing power is solely in the hands of the central government. The central government imposes a common tax function and gives a common grant to each region. Spending on the publicly provided good is the same across regions because the only source of funding is the uniform central grant. Regions have no decision-making power in this system; once the central tax function and central grant are set, the levels of both goods are determined.

To simplify the analysis we assume a proportional tax on income, $\phi\left(\omega_{i}\right)=t \omega_{i}$, where $t$ is the tax rate and is the same for all regional governments. Private consumption $c_{i}$ is equal to after-tax income $(1-t) \omega_{i}$. We define $g$ as the common level of publicly provided good realized in each region. Note that the variance in public spending $e$ is equal to zero in this case.

The decision variables of the government are the tax rate $t$ and the common level of publicly provided good $g$ for all regions. By the balanced budget restrictions, for every level of $t$, unique levels of publicly provided good $g$ and privately provided good $c_{i}$ are generated. Hence the set of allocations attainable through the centralized system can be parametrized by $t$. Assume that the central government's objective function is such that it does not choose Pareto-dominated allocations. This means that, given utility levels $u_{j}\left((1-\tilde{t}) \omega_{j}, \tilde{g}, \tilde{e}\right)$ of regions $j \neq i$, the following problem is solved:

$$
\begin{array}{ll} 
& \max \quad u_{i}\left((1-t) \omega_{i}, g, e\right) \\
\text { s.t. } & u_{j}\left((1-t) \omega_{j}, g, e\right) \geq u_{j}\left((1-\tilde{t}) \omega_{j}, \tilde{g}, \tilde{e}\right) \quad j \neq i \\
& n g=t \sum_{j=1}^{n} \omega_{j} \\
& g \geq 0 \\
& 0 \leq t \leq 1
\end{array}
$$

The Lagrangian for this problem is

$$
L(t, g, \lambda)=u_{i}\left((1-t) \omega_{i}, g, e\right)-\sum_{j \neq i}^{n} \alpha_{j}\left(\tilde{u}_{j}-u_{j}\left((1-t) \omega_{j}, g, e\right)\right)-\lambda\left(n g-t \sum_{j=1}^{n} \omega_{j}\right)
$$


which, ignoring constant terms, becomes

$$
L(t, g, \lambda)=\sum_{j=1}^{n} \alpha_{j} u_{j}\left((1-t) \omega_{j}, g, e\right)-\lambda\left(n g-t \sum_{j=1}^{n} \omega_{j}\right)
$$

where $\alpha_{i}=1$.

As the central government chooses to provide the same level of public good to all regions, all terms that involve the solidarity variable drop out.

The Kuhn Tucker conditions for a maximum are:

$$
\begin{aligned}
& \frac{\partial L}{\partial t}=-\sum_{j=1}^{n} \alpha_{j} \frac{\partial u_{j}}{\partial c_{j}} \omega_{j}+\lambda \sum_{j=1}^{n} \omega_{j} \leq 0 \\
& \frac{\partial L}{\partial g}=\sum_{j=1}^{n} \alpha_{j} \frac{\partial u_{j}}{\partial g}-\lambda n \leq 0 \quad i \in\{1,2, \ldots, n\}
\end{aligned}
$$

These inequalities hold with equality in an interior solution and we obtain

$$
\sum_{j=1}^{n} \alpha_{j} \frac{\partial u_{j}}{\partial c_{j}} \frac{\omega_{j}}{\sum_{j=1}^{n} \omega_{j}}=\frac{1}{n} \sum_{j=1}^{n} \alpha_{j} \frac{\partial u_{j}}{\partial g}
$$

This condition states that a weighted average of the regions' marginal contributions of the privately provided good, where the weights are each region's relative share of total wealth, is equal to the average marginal contribution of the publicly provided good to social welfare. In general, this will differ from the Pareto optimality condition in equation (10) and the centralized system will lead to inefficient outcomes.

\section{A.2 Decentralization}

Under this system the regions are free to tax themselves and set independently an appropiate level of public expenditure $g_{i}$. In choosing their actions, they are aware of the interdependence of their decisions and try to anticipate each other's behavior.

We model this case as a simultaneous game with public good expenditures as strategic variables. In order to find the Nash equilibrium we compute the best response function of region $i$ to a given level $g_{j}$ of the other region's public expenditure for each region $j$. The equilibrium is the solution of the following maximization problem: choose $c_{i}$ and $g_{i}$ so as to solve 


$$
\begin{array}{ll}
\max & u_{i}\left(c_{i}, g_{i}, e\right) \\
\text { s.t. } & c_{i}+g_{i}=\omega_{i} \\
& c_{i} \geq 0 \quad g_{i} \geq 0
\end{array}
$$

The Lagrangian expression for this problem is:

$$
L\left(c_{i}, g_{i}, \lambda_{i}\right)=u_{i}\left(c_{i}, g_{i}, e\right)-\lambda_{i}\left(c_{i}+g_{i}-\omega_{i}\right)
$$

and taking the first derivatives we obtain the Kuhn-Tucker first order necessary conditions:

$$
\begin{array}{lr}
\frac{\partial L}{\partial c_{i}}=\frac{\partial u_{i}}{\partial c_{i}}-\lambda_{i} \leq 0 & \text { with equality if } c_{i}>0 \\
\frac{\partial L}{\partial g_{i}}=\frac{\partial u_{i}}{\partial g_{i}}+\frac{\partial u_{i}}{\partial e} \frac{\partial e}{\partial g_{i}}-\lambda_{i} \leq 0 & \text { with equality if } g_{i}>0
\end{array}
$$

Assuming interior solutions for $c_{i}$ and $g_{i}$, from (23) and (24) we get

$$
\frac{\partial u_{i}}{\partial c_{i}}=\frac{\partial u_{i}}{\partial g_{i}}+\frac{\partial u_{i}}{\partial e} \frac{\partial e}{\partial g_{i}}=\frac{\partial u_{i}}{\partial g_{i}}+\frac{2}{n}\left(g_{i}-\bar{g}\right) \frac{\partial u_{i}}{\partial e}
$$

The marginal contributions of $c_{i}$ and $g_{i}$ to $i$ 's utility are equalized. What is ignored by the region is the impact of public good expenditure $g_{i}$ through $e$ on other regions' utilities (as required in the Pareto optimality condition in equation (10) ).

\section{A.3 Voluntary transfers}

Under this system, each regional government has complete freedom of choice over both goods. In addition, each can set interregional transfers from region $i$ to $j, s_{i j}$, which are voluntary transfers to solidarity. Thus, each regional government chooses $g_{i}, c_{i}$ and $s_{i j}($ for $j \neq i),{ }^{14}$ taking all other variables as given, so as to solve the following maximization problem

$$
\max u_{i}\left(c_{i}, g_{i}, e\right)
$$

\footnotetext{
${ }^{14}$ We assume $S_{i i}=0$.
} 


$$
\begin{array}{ll}
\text { s.t. } & c_{i}+g_{i}+\sum_{i \neq j} s_{i j}=\omega_{i}+\sum_{j \neq i} s_{j i} \\
& c_{i} \geq 0 \quad g_{i} \geq \sum_{j \neq i} s_{j i} \quad s_{i j} \geq 0
\end{array}
$$

The Nash equilibrium is obtained by solving simultaneously the $\mathrm{n}$ systems of necessary conditions. Setting up the Lagrangian of the $i$-th region:

$$
L\left(c_{i}, g_{i},\left\{s_{i j}\right\}_{j \neq i}, \lambda_{i}\right)=u_{i}\left(c_{i}, g_{i}, e\right)-\lambda_{i}\left(c_{i}+g_{i}+\sum_{i \neq j} s_{i j}-\omega_{i}-\sum_{j \neq i} s_{j i}\right)
$$

and taking first derivatives we obtain:

$$
\begin{array}{lr}
\frac{\partial L}{\partial c_{i}}=\frac{\partial u_{i}}{\partial c_{i}}-\lambda_{i} \leq 0 & \text { with equality if } c_{i}>0 \\
\frac{\partial L}{\partial g_{i}}=\frac{\partial u_{i}}{\partial g_{i}}+\frac{\partial u_{i}}{\partial e} \frac{\partial e}{\partial g_{i}}-\lambda_{i} \leq 0 & \text { with equality if } g_{i}>\sum_{j} s_{j i} \\
\frac{\partial L}{\partial s_{i j}}=\frac{\partial u_{i}}{\partial e} \frac{\partial e}{\partial g_{j}}-\lambda_{i} \leq 0 & \text { with equality if } s_{i j}>0 \text { for } j \neq i
\end{array}
$$

Assuming interior solutions for $c_{i}$ and $g_{i}$, and noting that $\frac{\partial e}{\partial g_{i}}=\frac{2}{n}\left(g_{i}-\bar{g}\right)$, from (29) and (30) we get

$$
\frac{\partial u_{i}}{\partial c_{i}}=\frac{\partial u_{i}}{\partial g_{i}}+\frac{2}{n}\left(g_{i}-\bar{g}\right) \frac{\partial u_{i}}{\partial e}
$$

The marginal contributions of $c_{i}$ and $g_{i}$ to $i$ 's utility are equalized, but, because each region acts independently to maximize its own utility, region $i$ does not take into account the impact of $g_{i}$ through $e$ on other regions' utilities as required in equation (10) for a Pareto optimum. ${ }^{15}$

\section{$\underline{\text { A.4 Guaranteed minimum }}$}

In this model the central government finances a uniform, minimum expenditure on the publicly provided good through a uniform grant and the regions are then free to tax themselves if they wish to spend more than the centrally funded minimum. We model this as a sequential process in which, in the first stage, the central government sets a common tax rate $t$ for all

\footnotetext{
${ }^{15}$ Inter-regional transfers will be positive only under reasonable and intuitive conditions. It can be shown that region $i$ sends transfers to region $j$ if $g_{i}>g_{j}$ and $g_{j}<\bar{g}$.
} 
regions. To keep the analysis very general we do not assume a specific objective for the central government, but rather obtain results for all possible values of $t$ and therefore any possible objective of the central government. The revenue is equally distributed so that the grant to any one region is equal to $\frac{1}{n} t \sum_{j=1}^{n} \omega_{j}=\frac{t}{n} \Omega$. This grant sets up a minimum level of the publicly provided good in all regions.

At a later stage, knowing the central tax rate and the corresponding grant, the regions are free to choose a higher level of the publicly provided good by raising additional revenue through local taxes. The second phase is modeled as a simultaneous game with the regions as players. The strategic variables are the levels of the privately provided good, $c_{i}$, and the locally financed publicly provided good, $g r_{i} \geq 0$. The level of the $i$-th region's publicly provided good is $g_{i}=g r_{i}+\frac{t}{n} \Omega$.

Given the value of the central government's strategic variable, the tax rate $t$, and taking the values of the other regions' strategic variables as given, the $i$-th regional government chooses $c_{i}$ and $g r_{i}$ so as to solve

$$
\begin{array}{rc}
\max & u_{i}\left(c_{i}, g r_{i}+\frac{t}{n} \Omega, e\right) \\
\text { s.t. } & c_{i}+g r_{i} \leq(1-t) \omega_{i} \\
& c_{i} \geq 0 \quad g r_{i} \geq 0
\end{array}
$$

The Lagrangian expression for this problem is:

$$
L\left(c_{i}, g r_{i}, \lambda_{i}\right)=u_{i}\left(c_{i}, g r_{i}+\frac{t}{n} \Omega, e\right)-\lambda_{i}\left(c_{i}+g r_{i}-(1-t) \omega_{i}\right)
$$

and taking the first derivatives we obtain the Kuhn-Tucker first order necessary conditions:

$$
\begin{array}{ll}
\frac{\partial L}{\partial c_{i}}=\frac{\partial u_{i}}{\partial c_{i}}-\lambda_{i} \leq 0 & \text { with equality if } c_{i}>0 \\
\frac{\partial L}{\partial g r_{i}}=\frac{\partial u_{i}}{\partial g_{i}}+\frac{\partial u_{i}}{\partial e} \frac{\partial e}{\partial g_{i}}-\lambda_{i} \leq 0 & \text { with equality if } g r_{i}>0
\end{array}
$$


If the minimum level guaranteed by the central government is below the level that the regional government would like to provide of that good, we will have an interior solution for $g r_{i}$. Assuming also an interior solution for $c_{i}$, from (36) and (37) we obtain

$$
\frac{\partial u_{i}}{\partial c_{i}}=\frac{\partial u_{i}}{\partial g_{i}}+\frac{2}{n}\left(g_{i}-\bar{g}\right) \frac{\partial u_{i}}{\partial e}
$$

At the margin, the decision of allocating resources between the privately and the publicly provided goods is identical to the decision in the decentralized case. Continuing to assume an interior solution for $c_{i}$, if the minimum level guaranteed by the central government is equal to or above the level that the regional government would like to provide, there will be no local provision of the publicly provided good, and thus we will have a corner solution with $g r_{i}=0$. In this case, from (36) and (37) we obtain

$$
\frac{\partial u_{i}}{\partial c_{i}} \geq \frac{\partial u_{i}}{\partial g_{i}}+\frac{2}{n}\left(g_{i}-\bar{g}\right) \frac{\partial u_{i}}{\partial e}
$$

and the central government guaranteed minimum level, because it takes low-spending regions beyond where they would be on their own, may result in an allocation that gets closer to the optimal allocation because the inequality in (39) may approach condition (10).

\section{A.5 Matching grants}

In this model regions are free to tax themselves to set an appropiate level of locally financed public expenditure, $g r_{i}$, and the central government provides a matching grant $z g r_{i}$, where $z \in[0,1]$ is the matching rate.

We model a sequential game with the central government as a Stackelberg leader. The central government chooses a matching rate $z$ and a tax rate $t$ that balances the budget $z \sum_{i=1}^{n} g r_{i}=t \sum_{i=1}^{n} \omega_{i}$.

At a later stage, knowing the tax rate and the corresponding subsidy, the regions decide the level of locally financed public expenditure $g r_{i} \geq 0$. The second phase is modelled as a 
simultaneous game with the regions as players. The strategic variables are the levels of private consumption, $c_{i}$, and the locally financed public expenditures, $g r_{i}$. The $i$-th region's total publicly provided good is $g_{i}=(1+z) g r_{i}$.

Given the value of the central government's strategic variables $z$ and $t$ and taking the values of the other regions' strategic variables as given, the $i$-th region chooses $c_{i}$ and $g r_{i}$ so as to solve

$$
\begin{array}{ll}
\max & u_{i}\left(c_{i},(1+z) g r_{i}, e\right) \\
\text { s.t. } & c_{i}+g r_{i} \leq(1-t) \omega_{i} \\
& c_{i} \geq 0 \quad g r_{i} \geq 0
\end{array}
$$

The Lagrangian expression for this problem is:

$$
L\left(c_{i}, g r_{i}, \lambda_{i}\right)=u_{i}\left(c_{i},(1+z) g r_{i}, e\right)-\lambda_{i}\left(c_{i}+g r_{i}-(1-t) \omega_{i}\right)
$$

and taking the first derivatives we obtain the Kuhn-Tucker first order necessary conditions:

$$
\begin{array}{ll}
\frac{\partial L}{\partial c_{i}}=\frac{\partial u_{i}}{\partial c_{i}}-\lambda_{i} \leq 0 & \text { with equality if } c_{i}>0 \\
\frac{\partial L}{\partial g r_{i}}=\frac{\partial u_{i}}{\partial g r_{i}}+\frac{\partial u_{i}}{\partial e} \frac{\partial e}{\partial g r_{i}}-\lambda_{i} \leq 0 & \text { with equality if } g r_{i}>0
\end{array}
$$

Assuming interior solutions for $c_{i}$ and $g r_{i}$, from (43) and (44) we get

$$
\frac{\partial u_{i}}{\partial c_{i}}=\frac{\partial u_{i}}{\partial g r_{i}}+\frac{\partial u_{i}}{\partial e} \frac{\partial e}{\partial g r_{i}}=\frac{\partial u_{i}}{\partial g_{i}}+\frac{2}{n}\left(g_{i}-\bar{g}\right) \frac{\partial u_{i}}{\partial e}
$$

Again, the marginal contributions of $c_{i}$ and $g r_{i}$ to $i$ 's utility are equalized, but region $i$ does not take into account the impact of the public good expenditure $g r_{i}$ through $e$ on other regions' utilities (as required in equation (10) derived from the first order conditions for a Pareto optimum). 


\section{APPENDIX B: Formal derivation of the measure of efficiency loss}

To measure the inefficiency of a given allocation $\left(\left(\bar{c}_{1}, \bar{g}_{1}\right),\left(\bar{c}_{2}, \bar{g}_{2}\right), \ldots . .,\left(\bar{c}_{n}, \bar{g}_{n}\right)\right)$ we take the vector of utilities $\left(\bar{u}_{1}, \bar{u}_{2}, \ldots, \bar{u}_{n}\right)$, where $\bar{u}_{i}=u_{i}\left(\bar{c}_{i}, \bar{g}_{i}\right)$ and find the minimum amount of resources necessary to attain these utility levels. ${ }^{16}$ Formally we solve the following problem

$$
\begin{aligned}
& \min \sum_{i=1}^{n} c_{i}+\sum_{i=1}^{n} g_{i} \\
& \text { s.t. } u\left(c_{i}, g_{i}\right)=\bar{u}_{i} \\
& c_{i} \geq 0 \quad g_{i} \geq 0
\end{aligned}
$$

Let $\omega(\bar{u})$ denote the level of resources that solves this problem, and let $\bar{\omega}=\sum_{i=1}^{n} \bar{c}_{i}+\sum_{i=1}^{n} \bar{g}_{i}$ denote the level of resources utilized by the given allocation. Then the difference $\bar{\omega}-\omega(\bar{u})$ is a measure of the resources wasted by the allocation $\left(\left(\bar{c}_{1}, \bar{g}_{1}\right),\left(\bar{c}_{2}, \bar{g}_{2}\right), \ldots .,\left(\bar{c}_{n}, \bar{g}_{n}\right)\right)$ and the efficiency loss is defined as $\frac{\bar{\omega}-\omega(\bar{u})}{\bar{\omega}}$

For the three systems where the central government can choose different values for its parameter, we calculate the efficiency loss to be the minimum value of the index for all parameter values. For the other two systems, the efficiency loss is calculated at the unique allocation under the system.

\footnotetext{
${ }^{16}$ This inefficiency measure is a simple instance (because there is a single commodity) of Debreu's (1951) coefficient of resource utilization.
} 


\section{References}

Alesina, A., Angeloni, I., Etro, F., 2005. "International Unions”, American Economic Review, 95(3), 602-615.

Alesina, A., Di Tella, R., MacCulloch, R., 2004. "Inequality and Happiness: Are Europeans and Americans Different?", Journal of Public Economics, 88(9-10), 2009-2042.

Besley, T., Coate, S., 2003. "Centralized versus decentralized provision of local public goods: a political economy approach”, Journal of Public Economics, 87(12), 2611-2637.

Brown, C., Oates, W., 1987. “Assistance to the Poor in a Federal System”, Journal of Public Economics, 32(3), 307-30.

Crémer, J., Palfrey, T.R., 2000. "Federal Mandates by Popular Demand”, Journal of Political Economy,108(5), 905-927.

Debreu, G., 1951. “The Coefficient of Resource Utilization”, Econometrica, 19(3), 273-292.

Debreu, G., Scarf, H. 1963 "A Limit Theorem on the Core of an Economy”, International Economic Review, 4(3), 235-246.

Garcia-Milà, T., McGuire, T., 2004. "Solidarity and Fiscal Decentralization", Proceedings 96th Annual Conference on Taxation, Chicago, Illinois, November 13(15), 2003. Washington, DC: National Tax Association.

Gramlich, E., 1985. "Reforming U.S. Federal Fiscal Arrangements", American Domestic Priorities: An Economic Appraisal, J. Quigley and D. Rubinfeld, eds. Berkeley, CA: University 
of California Press, 34-69.

Gruber, J., 2005. Public Finance and Public Policy, New York: Worth Publishers.

Lockwood, B., 1999. "Interregional Insurance”, Journal of Public Economics, 72(1), 1-37.

Konow, J., 2003. "Which is the Fairest One of All? A Positive Analysis of Justice Theories", Journal of Economic Literature, XLI(4), 1188-1239.

Musgrave, R.A., Musgrave, P.B., 1989. Public Finance in Theory and Practice, $5^{\text {th }}$ Edition, New York: McGraw-Hill, Inc.

Oates, W., 1972. Fiscal Federalism, New York: Harcourt, Brace Jovanovich.

Oates, W., 1999. “An Essay on Fiscal Federalism”, Journal of Economic Literature, XXXVII(3), 1120-1149.

OECD, 2008a. "Education at a Glance 2008: OECD Indicators", http://www.oecd.org/edu/eag2008

OECD, 2008b. "OECD Health Data 2008: Statistics and Indicators for 30 Countries", http://www.oecd.org/health/healthdata

Pauly, M. V., 1973.“Income Redistribution as a Local Public Good”, Journal of Public Economics, 2(1), 35-58. 
Persson, T, Tabellini, G., 1996. "Federal Fiscal Constitutions: Risk Sharing and Redistribution”, Journal of Political Economy, 104(4), 979-1009.

Tobin, J., 1970. “On Limiting the Domain of Inequality”, Journal of Law and Economics 13(2), 263-277. 